\title{
Mine haul road fugitive dust emission and exposure characterisation
}

\author{
R.J. Thompson ${ }^{1} \&$ A.T. Visser ${ }^{2}$ \\ ${ }^{\prime}$ Department of Mining Engineering \\ ${ }^{2}$ Department of Civil \& Bio-systems Engineering. \\ University of Pretoria, South Africa.
}

\begin{abstract}
Excessive dust generation from unpaved mine haul roads is a problem common to most surface mining operations and especially so in semi-arid and arid areas. Optimal wearing course material selection parameters reduce, but do not totally eliminate the potential to produce dust. Mines rarely have optimally designed and maintained roads, and the problem of identifying the haul road dust defect, quantifying its impact on health-risk and assigning remediation priorities within the constraints of limited capital and manpower is problematic. This paper describes fugitive dust emission and operator-exposure characteristics associated with mine haul trucks running on unpaved mine haul roads in Sub-Saharan Africa. Following a description of fugitive dust emission rate models developed, the methodology of operator-exposure profiling by quantitative dust sampling for airborne particulate matter is described. Typical Air Quality Indices that a haul truck driver would be exposed to during a typical cycle are reported following the South African Mines and Works Act (78/1973) Guidelines. The majority of truck driver exposure was attributable to loading and dumping activities with the haul roads and ramps themselves accounting for between $10 \%$ $15 \%$ each of the total exposure (open cab) and 5-10\% each (closed cab). A 30\%$55 \%$ reduction in dust concentrations measured in a closed cab as compared to an open cab were realised. Through the combination of these models with the results of quantitative exposure profiling, it is shown how a mine can effectively reduce worker exposure and health-risk by adopting appropriate haul road dust palliation strategies.
\end{abstract}




\section{Environmental Health Risk}

\section{Introduction}

The South African coal mining sector in 2002 produced approximately $168 \mathrm{~m}$ run-of mine tons from surface mines, which require, inter alia, the transport of raw coal from the pit to the loading or transfer point. This is accomplished by large haul trucks running on unpaved haul roads that have, at best, been empirically designed with little or no recognition of the consequences of inadequate design on safety, health or the environment. From a South African strip coal mining perspective, in terms of haul truck-based transport of coal alone, over 800000 truck trips representing over 7,2m truck kilometers are made per annum, the greater proportion of truck kilometers, and hence fugitive dust emissions, being centered on the Highveld of the Mpumalanga Province, as shown in Figure 1.

Dust, created through the mechanical disintegration of particulate matter, is a problem common to most surface mining operations and current wearing course material selection parameters reduce, but do not totally eliminate the potential to produce dust (Thompson \& Visser [1, 2]) and considerable time and expenditure is nevertheless applied to the reduction of vehicle generated haul road dust. The broader environmental effects of dust have been reviewed by Amponsah-Dacosta [3] who conducted an emission inventory for a South African coal strip mining operation. The emission inventory was based on a characterisation of open dust sources over a specific interval of time, to produce a dispersion model to enable predictions to be made concerning ambient pollution levels and the identification of major control areas. The analysis, conducted according to USEPA [4] guidelines, found that $93,3 \%$ of the total emissions from the mine were attributable to dust generated from the mine haul road (the next highest source, at $2,7 \%$, being attributable to top soil handling). Although a high tonnage operation, the road network on the mine was similar to other such operations and it was concluded that emissions from the road network would be typical of most surface coal mines, when calculated on a percentage of total emissions basis.

For existing operations, which may not have optimally designed and maintained road networks, identifying existing deficiencies, quantifying their impact and assigning priorities within the constraints imposed by limited capital and manpower is problematic. This is reflected in the fact that most surface mine operators agree dust-free roads are desirable, but find it difficult to translate this into cost-effective remediation strategy.

\subsection{Aim and scope of paper}

This paper describes mine road fugitive dust emission and truck operatorexposure characterisation in Sub-Saharan Africa. Following a description of fugitive dust emission rate models developed, the methodology and modelling of operator-exposure profiles by quantitative dust sampling for airborne particulate matter is described. Through the combination of these models with the results of quantitative exposure profiling, it is shown how a mine can effectively reduce worker exposure and health-risk associated with haul road dust generation. 


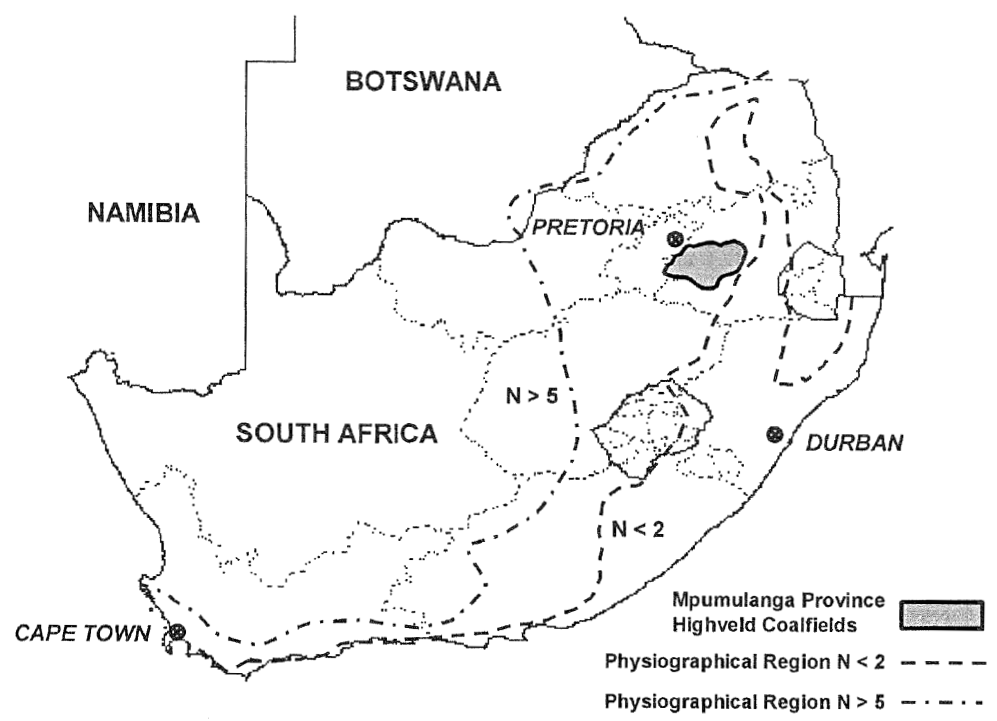

Figure 1: Location of South Africa's major coalfields and their associated physiographical region, following Weinert [5]

\section{Fugitive dust emission modelling}

Most mine untreated wearing course materials exhibit excessive dustiness and thus there is the need to reduce the dust defect through some form of palliation. Numerous dust palliatives exist, of which water-spraying is the most common solution applied. Unfortunately, most mine haul road dust palliative testing to date has been conducted on an ad-hoc basis with little or no quantitative health or exposure data generated and thus no dust management strategy determined. The first step in assessing the problem and characterising dust generation and exposure, is therefore to formalise an experimental design.

\subsection{Experimental design}

The experimental design adopted for the study entailed the analysis of a number of strip coal mine haul roads which covered the fullest range of factors controlling fugitive dust emission characteristics [6]. Climate variation as a factor was eliminated from the study since most mines were located in the same physiographical region, as was the road traffic volume factor, primarily since the test site locations did not enable similar materials to be tested under a range of traffic conditions due to the variable nature of the traffic itself. Traffic volume and road maintenance activities were thus recorded as independent variables for each test site. 


\section{Environmental Health Risk}

\subsubsection{Airborne particulate matter qualitative dust sampling methodology}

The approach incorporated the development of benchmarkable generic dust defect scores, to initially characterise the dustiness of a range of mine road wearing course materials and treatments, based on typical dust concentrations of the minus $10 \mathrm{~m}$ dust fraction. This fraction was chosen since, from a safety (visibility) perspective, particles that become suspended for a noticeable length of time are generally $<30 \_\mathrm{m}$ in diameter. Additionally, the USEPA national PM-10 (particulate matter no greater than 10 microns in aerodynamic diameter) emission factors recognised that the respirable pollutant fraction (PM-10) from both industrial (mine) and public unpaved roads contribute most to the PM-10 emission total and, from a health point of view, the reduction of this respirable fraction is of particular importance. Using the minus $10 \mathrm{~m}$ dust fraction to characterise the dust defect score extends the applicability the data to enable health or exposure-based analysis of truck drivers to be undertaken.

\subsubsection{Airborne particulate matter quantitative dust sampling methodology}

The health risk associated with exposure to fugitive dust emissions from mine haul roads was assessed through a number of sampling exercises undertaken in mine haul truck cabs, over a typical operating cycle on the roads previously analysed and modelled qualitatively for fugitive dust generation. The methodology adopted was based on in-cab sampling of the respirable dust fraction concentration $\left(-10 \_\mathrm{m} / \mathrm{m}^{3}\right)$ using the Hund Tyndalometer [7]. Data were recorded for the following general hauling activities, both with laden and unladen trucks;

- Travelling on haul road

- Travelling on ramp

- Waiting, spotting and loading at loading area

- Waiting and tipping at dump or tip

Seven test sites were evaluated, covering a range of vehicle and haul road conditions. In each case, the road was evaluated in it's dry base-case (unwatered or untreated) condition. In addition to the dust concentration, the following parameters, which could affect air quality in the haul truck, were also recorded;

- Number of vehicle interactions on the road (either following another vehicle or passing another truck in the opposite direction)

- Sealed (closed air conditioned) cab or open (windows open) cab

- Average time taken to complete each hauling activity.

To determine the typical air quality indices (AQI's) that a haul truck driver would be exposed to during a typical cycle, a calculation procedure as specified in the Guidelines for the Gravimetric Sampling of Airborne Particulates for Risk Assessment in Terms of the Occupational Diseases in Mines and Works Act (78/1973) Parent Document [8] was adopted. The sampling methodology did not conform to that outlined in the document since personal gravimetric sampling devices would not allow for intermittent reading and the interrogation of data for each specific activity. The data thus recorded should therefore not be seen as equivalent to that recorded by gravimetric means, primarily because the analysis assumes that the average values obtained over two repeats of the test (of 
approximately 30-62 minutes duration) and the associated AQI's will apply over a full shift.

Data relating to the specific pollutant threshold limit values was obtained from the Guidelines Document [8] (Supporting Document No.2, 1994) for alpha quartz content data relating to samples, taken on the mine for the same statistical population of which haul truck drivers are members. A threshold limit value time-weighted average concentration of $2,0 \mathrm{mg} / \mathrm{m}^{3}$ of the respirable fraction was used where alpha quartz concentrations did not exceed $5 \%$, or $0,1 \mathrm{mg} / \mathrm{m}^{3}$ was adopted (for alpha quartz $>5 \%$ ). AQI was calculated from the time-averaged dust concentration over the complete cycle of activities, using appropriate threshold limit values as outlined above.

The AQI was assessed in terms of the recommended good practice, inspection and cessation of work levels of $<0,5,>1,0$ and $>5,0$ respectively, for each of the closed or open cab tests and for the individual components of the haul cycle, and following the approach outlined in the Draft Guidelines for the Compilation of a Mandatory Code of Practice for an Occupational Hygiene Program (No.1 Personal Exposure to Airborne Pollutants, Department of Minerals and Energy, draft amendment 6 of 1999) [9].

\section{Modelling dustiness as a function of wearing course material and vehicle speed}

To provide an initial estimate of the dustiness associated with a particular wearing course material, seven test sites were selected from which data was recorded and analysed to model three parameters;

- Mass of dust as loose material on the road $\left(\mathrm{g} / \mathrm{m}^{2}\right)$

- Total dustiness (from consideration of peak and period of truck dust plume)

- Total dustiness as a function of vehicle speed and mass of loose material on the road.

By combining each of the above models, a preliminary estimate of dustiness associated with vehicle type, speed and wearing course was found, from which the required watering frequency (for water-spray based dust suppression) was determined, being based on the road-user defined intervention level (maximum allowable dustiness) of $23,5 \mathrm{mg} / \mathrm{m}^{3}$ for $-10 \mathrm{~m} / \mathrm{m}^{3}$ dust. Figure 2 shows the measured dust increase with time for a particular test site and vehicle, together the model estimation developed.

Table 1 summarises the application of these models to a typical South African surface mine operating a well built and maintained haul road. Using water-based spraying for dust suppression, the re-watering interval required in typical summer conditions is approximately 33 minutes, extending to 63 minutes in winter. When using bottom-dump trucks of a similar capacity, due to the increase in the number of wheels and the vehicle footprint area, greater concentrations of dust are more rapidly generated after watering and as such watering frequency increases to every 21 minutes in summer and 41 minutes in winter for the same traffic volumes and road wearing course material parameters. 
108 Environmental Health Risk

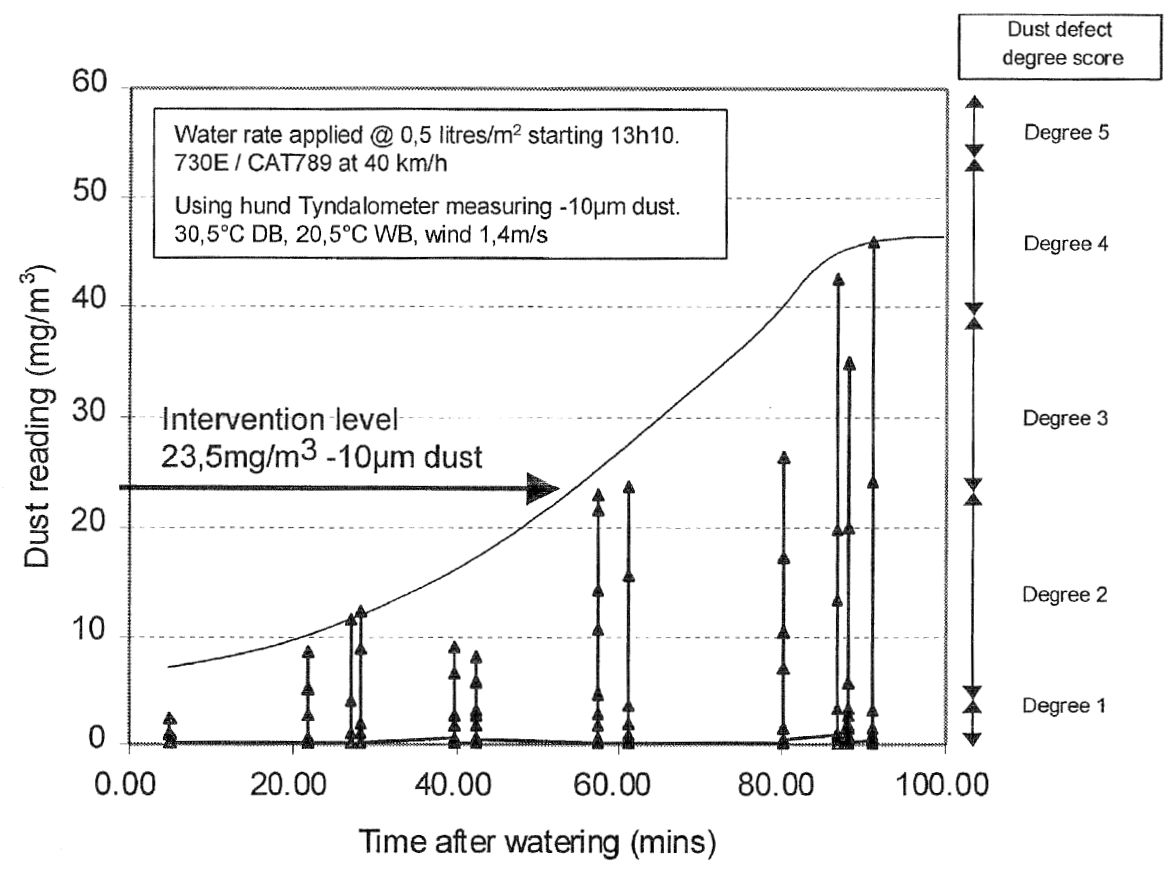

Figure 2: Typical dust profile of haul road, showing rate of increase in dustiness with time, and road-user defined intervention level (maximum allowable dust defect) of $23,5 \mathrm{mg} / \mathrm{m}^{3}$ for $-10 \mu \mathrm{m}$ dust.

Table 1: Model results for typical haul road watering frequency simulation for southern Africa Highveld conditions

Water spray palliation model results

\begin{tabular}{|c|c|c|c|c|}
\hline \multirow[b]{2}{*}{$\begin{array}{l}\text { Season and monthly } \\
\text { evaporation rate }(\mathrm{mm} / \mathrm{mth})\end{array}$} & \multicolumn{2}{|c|}{ 6-wheel truck } & \multicolumn{2}{|c|}{ 10-wheel truck } \\
\hline & $\begin{array}{l}\text { Summer } \\
(260)\end{array}$ & $\begin{array}{l}\text { Winter } \\
(140)\end{array}$ & $\begin{array}{l}\text { Summer } \\
(260)\end{array}$ & $\begin{array}{l}\text { Winter } \\
(140)\end{array}$ \\
\hline Time to zero palliation (mins) & 96.3 & 184.2 & 96.3 & 184.2 \\
\hline Percent palliation required ${ }^{1}$ & 65 & 77 & 65 & 77 \\
\hline Reapplication interval ${ }^{2}$ (mins) & 33 & 63 & 21 & 41 \\
\hline
\end{tabular}

Notes

1. Average percent reduction in dustiness (compared with base-case untreated conditions) to maintain a dust defect score that at no time exceeds $23.5 \mathrm{mg} / \mathrm{m}^{3}$ $10 \mu \mathrm{m}$ dust.

2. For a single application of 0.5 litres $/ \mathrm{m}^{2}$ water. 
The combinations of models previously described gave an insight into the required watering frequencies for various combinations of vehicle types, speeds, traffic volumes, wearing course material types and evaporation rates. This data can then be used as a base-case scenario with which to compare haul truck driver exposure to haul road respirable dust, under the same road dust management and operating conditions. This aspect of the work is more fully developed by Thompson \& Visser [6].

\section{Evaluation of haul truck driver exposure to haul road respirable dust}

The health risk associated with exposure to fugitive dust emissions from mine haul roads was assessed through a number of sampling exercises undertaken in mine haul truck cabs, over a typical operating cycle. Seven test sites were evaluated in terms of the typical AQI's that a truck driver would be exposed to during a normal working day, linking sources of dust to overall AQI contribution during the haul cycle. Using the previously established intervention level and reapplication frequencies to generate an average degree of dust palliation, the impact of this reduced dustiness can be assessed in the light of expected improvements in the overall $\mathrm{AQI}$.

Figure 3 summarises the results of the respirable dust assessments for a selection of seven test sites evaluated, following the experimental methodology and sampling procedures described earlier.

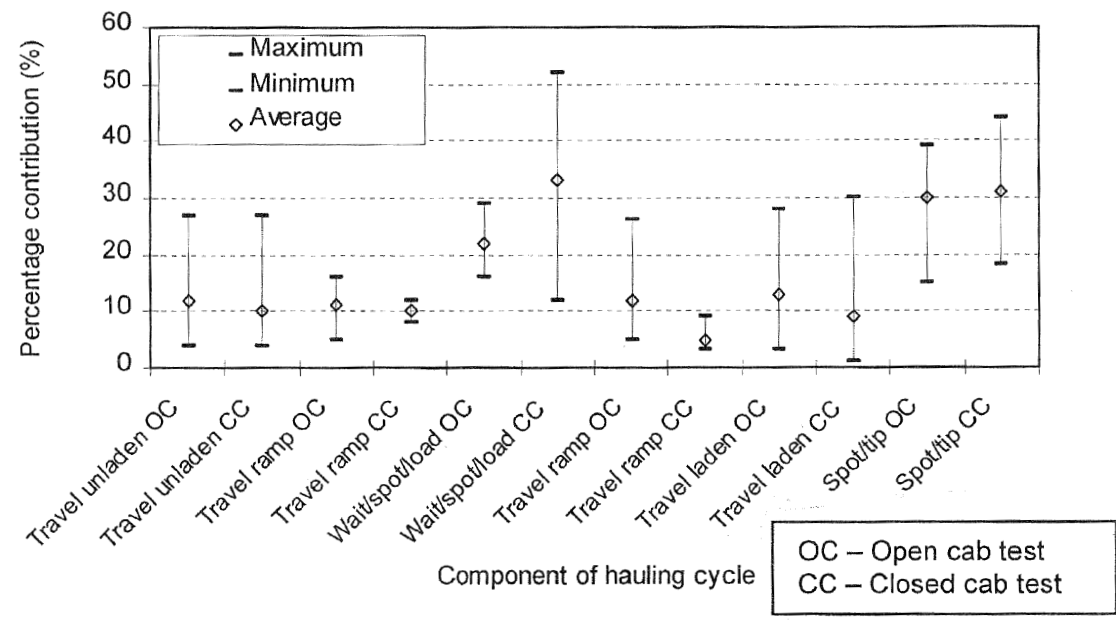

Figure 3: Variation in percentage source contribution to time-weighted in-cab (open and closed) respirable dust concentrations during typical hauling cycle

The percentage contribution is shown for each cycle activity, calculated from the time-weighted average concentrations of respirable dust recorded, for both open and closed (sealed) cab conditions. Although closed cab conditions 